\title{
Ethanol production from corn stover pretreated by electrolyzed water and a two-step pretreatment method
}

\author{
WANG XiaoJuan ${ }^{1,2}$, FENG Hao ${ }^{2} \&$ LI ZhiYi $^{1 *}$ \\ ${ }^{1}$ School of Chemical Machinery, Dalian University of Technology, Dalian 116023, China; \\ ${ }^{2}$ Institute for Genomic Biology, University of Illinois at Urbana-Champaign, Urbana, IL, USA
}

Received September 19, 2011; accepted November 14, 2011; published online March 28, 2012

\begin{abstract}
Pretreatment is one of the most important unit operations for ethanol production from biomass feedstocks. In this study, corn stover was used as a feedstock to examine the effectiveness of two pretreatments: electrolyzed water pretreatment and a two-step pretreatment. Electrolyzed water was employed as a catalyst to conduct one-step pretreatment of corn stover at three temperatures $\left(165,180\right.$ and $\left.195^{\circ} \mathrm{C}\right)$ and three treatment times $(10,20$ and $30 \mathrm{~min})$. During the two-step pretreatment process, an organic alkaline solution of $1 \%(\mathrm{w} / \mathrm{w}) \mathrm{NaOH}$ in $70 \%(\mathrm{w} / \mathrm{w})$ ethanol was used for lignin removal in the first step, followed by a second step using hot water. No furfural or 5-hydroxymethyl furfural was detected in the hydrolysates from both pretreatment methods when the detection limit of the HPLC was $0.2 \mathrm{~g} / \mathrm{L}$. The highest glucan conversion yields were $83 \%$ obtained at $195^{\circ} \mathrm{C}$ for 30 min with acidic electrolyzed water and $83 \%$ by the two-step process, where the second step of the pretreatment was at $135^{\circ} \mathrm{C}$ for $30 \mathrm{~min}$. The hydrolyzates from the two pretreatment methods showed good performance in Saccharomyces cerevisiae fermentation tests. The two new methods may provide promising alternatives for the pretreatment of biomass for ethanol production.
\end{abstract}

ethanol, biomass, pretreatment, inhibitor

Citation: Wang X J, Feng H, Li Z Y. Ethanol production from corn stover pretreated by electrolyzed water and a two-step pretreatment method. Chin Sci Bull, 2012, 57: 1796-1802, doi: 10.1007/s11434-012-5079-1

Liquid fuels production from renewable sources has drawn special attention from scientists and engineers around the world. In the biochemical route, where a biomass feedstock is broken down into its component sugars for fermentation, three major processes are involved, including pretreatment, enzymatic hydrolysis, and fermentation. The purpose of pretreatment is to loosen the macro- and micro-structures of the biomass by partial removal of lignin and hemicellulose, and partial decrystallization of cellulose, with the purpose of increasing enzymatic hydrolysis rate and yield. However, breaking the natural defense system of plant cells has been challenging and therefore harsh conditions such as strong acid and base, and high temperatures have to be used. Consequently, besides the cost of the feedstock, pretreatment has become the single most expensive unit operation [1,2].

During the past decades, numerous pretreatment methods

*Corresponding author (email: lizy@dlut.edu.cn) have been proposed and tested. Steam explosion with or without catalyst and diluted acid are among the oldest pretreatment methods and these have been investigated for over 50 years for the pretreatment of various biomasses [3-7]. Hot water and ammonia fiber explosion (AFEX) are promising pretreatment methods developed over the last two decades [8,9]. Other methods, such as lime, ionic liquids, and cellulose solvents have also been extensively investigated. Many of the pretreatment methods, however, are associated with limitations for large scale production, such as use of corrosive chemicals, potential environmental pollution, production of inhibitory compounds, solvent recovery, and high capital or operational costs.

Scientists at the University of Illinois have proposed a new pretreatment method using electrolyzed water as a catalyst $[10,11]$. Electrolyzed water pretreatment does not involve chemical additions such as acid, lime or ammonia that would increase costs and must be neutralized or recovered. 
In addition, there are less degradation products during the process, according to our preliminary research.

The concept of the biorefinery, introduced by the National Renewable Energy Laboratory (NREL), is analogous to today's petroleum refineries, which produce multiple fuels and products from petroleum. A biorefinery will make use of every component in the biomass to produce fuels and chemicals. Lignin can be incorporated into various polymer materials, such as silicate clays and can be used for the production of chemicals and high energy-content fuels. Lignin is considered an obstacle to realizing effective enzymatic hydrolysis and its removal is one of the goals of a successful pretreatment process [12,13]. A two-step pretreatment method was proposed to partially separate lignin from biomass, providing improved accessibility of biomass to enzymes to increase sugar yield. In this study, electrolyzed water pretreatment and an alkaline-organic solution two-step method were tested using corn stover as a feedstock.

\section{Materials and methods}

\subsection{Materials}

Corn stover was kindly provided by the Institute of Genomic Biology, University of Illinois at Urbana-Champaign. The samples were ground using a Thomas-Wiley mill (model 4) to pass a $1 \mathrm{~mm}$ sieve and stored at $-20^{\circ} \mathrm{C}$. The composition of corn stover was $41.16 \%$ glucan, $20.20 \%$ xylan and $17.25 \%$ lignin, determined by the NREL method [14-16].

Cellulase (Spezyme CP) and $\beta$-glucosidase (Novo 188) solutions were purchased from Sigma (St. Louis, MO, USA) and the activities of the enzymes were determined using methods from the National Renewable Energy Laboratory in the USA [17], the literature [18], and assays provided by the company. The release of reducing sugars in the cellulase assay was determined as described by Miller [19], while the release of glucose in the $\beta$-glucosidase assay was determined by a Glucose Assay kit purchased from Sigma. All the other reagents were from either Sigma-Aldrich or Fisher Scientific (New Bruswick, NJ, USA) unless specifically noted.

The acidic electrolyzed water (AEW) and alkaline electrolyzed water (ALEW) were generated by a ROX-20TA-U water electrolyzer (Hoshizaki America, Inc., South Peachtree City, GA). The AEW has a pH of 2.6, and an oxidation reduction potential (ORP) of $>1100 \mathrm{mV}$, while the ALEW has a $\mathrm{pH}$ of 11.7 and an ORP of $<-795 \mathrm{mV}$. The $5 \mathrm{~mol} / \mathrm{L} \mathrm{NaOH}$ and $\mathrm{HCl}$ solutions were prepared for $\mathrm{pH}$ adjustment during the experiments.

\subsection{Pretreatment}

In the one-step electrolyzed water pretreatment, corn stover was treated with AEW and ALEW at three different tem- peratures $\left(165,180\right.$ and $\left.195^{\circ} \mathrm{C}\right)$ and three time periods $(10$, 20 and $30 \mathrm{~min})$. The solid loading was $12.5 \%(\mathrm{w} / \mathrm{w})$, achieved by adding $5 \mathrm{~g}$ corn stover (dry weight) to each tubular reactor to obtain a total slurry mass of $40 \mathrm{~g}$. All pretreatments were conducted in tubular reactors with OD of 1 inch $(2.54 \mathrm{~cm})$ and length of 7 inch $(17.78 \mathrm{~cm})$. A SBL-2D fluidized sand bath $(4000 \mathrm{~W}$, Techne Inc. Burlington, NJ, USA) equipped with a TC-8D temperature controller was used for heating. Corn stover was presoaked in AEW or ALEW for $4 \mathrm{~h}$ in the reactors before being placed into the sand bath. At first, the temperature of the sand bath was set at a temperature that was $20^{\circ} \mathrm{C}$ higher than the designated reaction temperature. When the bath reached the set temperature, the heater was turned off and the tubular reactors containing corn stover slurry were placed into the sand bath. The reaction start time was defined as the moment when the temperatures of both the tubular reactors and the sand bath reached the reaction temperature. Immediately following the reaction, the reactors were submerged into ice water to stop the reaction.

For the alkaline-organic solution two-step pretreatment, a solution of $1 \%(\mathrm{w} / \mathrm{w}) \mathrm{NaOH}$ and $70 \%(\mathrm{w} / \mathrm{w})$ ethanol was used in the first step. The treatment was conducted in a sealed flask at $80^{\circ} \mathrm{C}$ and $150 \mathrm{r} / \mathrm{min}$ for $2 \mathrm{~h}$ with a solidliquid loading of 5:50 $(\mathrm{g}: \mathrm{mL})$, achieved by soaking $5 \mathrm{~g}$ corn stover (dry weight) in $50 \mathrm{~mL} \mathrm{NaOH}$-ethanol solution. After incubation, the slurry was subjected to centrifugation. The supernatant was removed for lignin recovery, while the solid was transferred with deionized (DI) water into tubular reactors for the second pretreatment. The solid loading was controlled at $10 \%(\mathrm{w} / \mathrm{w})$, by adding $5 \mathrm{~g}$ dry corn stover from the first pretreatment into $45 \mathrm{~g}$ DI water. The second step pretreatment was conducted in water at 4 different temperatures $\left(120,135,150\right.$ and $\left.165^{\circ} \mathrm{C}\right)$ for $30 \mathrm{~min}$ using the same sand bath system described before. After the second pretreatment, the slurry was centrifuged. The solid residue was subjected to enzymatic hydrolysis.

\subsection{Hydrolysis}

For each reactor in the one-step pretreatment, the pretreated slurry was diluted and washed into a $100 \mathrm{~mL}$ VITLAB flask with a sodium citrate buffer $(\mathrm{pH} \mathrm{5.0,100} \mathrm{mmol/L})$. The $\mathrm{pH}$ of the slurry was adjusted to 5.0. After loading the enzymes, the total weight of the slurry was adjusted to $100 \mathrm{~g}$ with

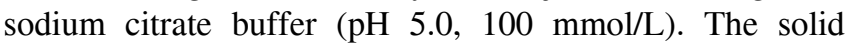
loading of enzymatic hydrolysis was $5 \%(\mathrm{w} / \mathrm{w})$.

In the alkaline-organic solution two-step pretreatment, the solid residue after the second pretreatment was washed into a $100 \mathrm{~mL}$ VITLAB flask by sodium citrate buffer $(\mathrm{pH}$ $5.0,100 \mathrm{mmol} / \mathrm{L}$ ). After adjusting the $\mathrm{pH}$ and adding enzyme solutions, the solid loading was maintained at 5:65 ( $\mathrm{g}: \mathrm{g}$ ), by adding $5 \mathrm{~g}$ dry corn stover to the buffer and enzyme solutions to obtain a slurry of $65 \mathrm{~g}$.

The enzyme loading was the same during the hydrolysis 
for both pretreatment methods: 15 FPU cellulase/g glucan, 40 unit $\beta$-glucosidase/g glucan. FPU stands for filter paper unit which means the amount of enzyme release $1 \mu \mathrm{mol}$ of glucose from filter paper (Whatman No.1) in $1 \mathrm{~min}$. One unit of $\beta$-glucosidase acitivity is defined as the enzyme amount, which converts $1 \mu \mathrm{mol}$ of cellubiose to $2 \mu \mathrm{mol}$ of glucose in $1 \mathrm{~min}$. The hydrolysis for the one-step pretreatment was conducted at $50^{\circ} \mathrm{C}, 200 \mathrm{r} / \mathrm{min}$ for $120 \mathrm{~h}$, while the hydrolysis for the two-step pretreatment was at $50^{\circ} \mathrm{C}, 200$ $\mathrm{r} / \mathrm{min}$ for $96 \mathrm{~h}$.

Cellulose conversion yield $(y)$ can be calculated as:

$$
y=\frac{C(\mathrm{~g} / \mathrm{L}) \times V(\mathrm{~L})}{1.11 \times M(\mathrm{~g})},
$$

where, 1.11 is the conversion efficiency of cellulose converting into glucose, $C$ is the glucose concentration in the hydrolysate, $V$ is the volume of the hydrolysate, and $M$ is the original cellulose in added corn stover.

\subsection{Fermentation}

S. cerevisiae (Baker's yeast) was used for the fermentation, and the experiments were conducted at $30^{\circ} \mathrm{C}$ and $200 \mathrm{r} / \mathrm{min}$ for $96 \mathrm{~h}$ in a shaker water bath (Aquatherm water bath shaker, New Brunswick Scientific Co. INC). A $30 \mathrm{~g} / \mathrm{L}$ glucose solution was used as a fermentation control and was prepared with $1 \mathrm{~g} / \mathrm{L}$ yeast extract, $0.5 \mathrm{~g} / \mathrm{L}\left(\mathrm{NH}_{4}\right)_{2} \mathrm{SO}_{4}, 0.025$ $\mathrm{g} / \mathrm{L} \mathrm{MgSO}_{4} \cdot 7 \mathrm{H}_{2} \mathrm{O}$, and $1.38 \mathrm{~g} / \mathrm{L} \mathrm{NaH}_{2} \mathrm{PO}_{4}$ [20]. The hydrolysates were used without concentration and detoxification and no nutrients were added to the hydrolysates. The hydrolysates and the control glucose solution were adjusted to $\mathrm{pH} 5.5$ and then autoclaved. Before fermentation, $1 \mathrm{~g}$ of Baker's yeast was mixed with $5 \mathrm{~mL}$ DI water and placed in the water bath at $30^{\circ} \mathrm{C}$ and $200 \mathrm{r} / \mathrm{min}$ for half an hour for activation. The $1 \mathrm{~mL}$ yeast solution was then placed into each fermentation flask which contained $70 \mathrm{~mL}$ glucose control or hydrolysate.

The productive yield was used for the test of fermentation efficiency and calculated as:

$$
Y=\frac{C_{\mathrm{ec}}(\mathrm{g} / \mathrm{L})}{0.51 \times C_{\mathrm{igc}}(\mathrm{g} / \mathrm{L})},
$$

where 0.51 is the theoretical ethanol yield $(\mathrm{g} / \mathrm{L})$ generated per $\mathrm{g} / \mathrm{L}$ glucose; $Y$ is productive yield; $C_{\mathrm{ec}}$ is final ethanol concentration; and $C_{\mathrm{igc}}$ is initial glucose concentration.

\subsection{Analysis}

Monosaccharide and inhibitors concentrations were analyzed by a Waters HPLC system (Milford, MA, USA) consisting of an e2695 separation module, refractive index detector and UV detector (Waters 2414) monitored by Empower pro software version 6.2. Sugars were estimated using Aminex HPX-87P (300 mm $\times 7.8 \mathrm{~mm})$ equipped with a Micro-guard Carbo-P cartridge $(30 \mathrm{~mm} \times 4.6 \mathrm{~mm})$ from Bio-Rad (Hercules, CA, USA). The temperatures of the column and the refractive index detector were kept at 85 and $50^{\circ} \mathrm{C}$, respectively, while the cartridge was at room temperature. Ultra-pure grade water $(0.45 \mu \mathrm{m}$ filtered and $18.2 \Omega / \mathrm{cm}$ conductivity, $0.6 \mathrm{~mL} / \mathrm{min}$ ) was used as a mobile phase. Ethanol, acetic acid, HMF (5-hydroxymethyl furfural), and furfural concentrations were determined using the same HPLC system but with an Aminex HPX-87H column. The column temperature was $65^{\circ} \mathrm{C}$. The mobile phase was $0.5 \mathrm{~mol} / \mathrm{L} \mathrm{H}_{2} \mathrm{SO}_{4}$ solution at a flow rate of $0.6 \mathrm{~mL} / \mathrm{min}$.

\section{Results and discussion}

\subsection{Electrolyzed water pretreatment}

The sugar concentrations after $120 \mathrm{~h}$ hydrolysis from corn stover pretreated by the electrolyzed water one-step pretreatment are shown in Figure 1. Figure 1(a) and (b) are the concentrations of glucose and xylose from the hydrolysates treated by AEW, while Figure 1(c) and (d) are for those treated by ALEW. The glucose concentration in the hydrolysate increased as the pretreatment temperature and pretreatment time increased (Figure 1(a) and (c)). The highest glucose concentrations in the AEW and ALEW experiments were obtained at the same conditions: $195^{\circ} \mathrm{C}$ and $30 \mathrm{~min}$, reaching 18.9 and $18.5 \mathrm{~g} / \mathrm{L}$, respectively. As a result, the highest glucan conversion, $83 \%$, was obtained at $195^{\circ} \mathrm{C}, 30$ min for the AEW treatment. Noticeably, for xylose (Figure 1 (b) and (d)), the highest yield was seen after a $20 \mathrm{~min}$ treatment at $195^{\circ} \mathrm{C}$, i.e., 8.5 and $8.0 \mathrm{~g} / \mathrm{L}$ for the $\mathrm{AEW}$ - and ALEW-pretreated samples, respectively. At 165 and $180^{\circ} \mathrm{C}$, the xylose concentration increased with time. However, at $195^{\circ} \mathrm{C}$, the xylose concentration reached a maximum at 20 min and a prolonged treatment for $30 \mathrm{~min}$ resulted in a decrease in xylose concentration, which was more pronounced for the AEW treatment (Figure 1(b)). The xylose lost after a 30 min treatment might be caused by degradation of hemicellulose at $195^{\circ} \mathrm{C}$. It has been reported that the degradation of xylose is much easier and faster than that of glucose [21-24].

\subsection{Two-step pretreatment}

Figure 2 shows the result of the sugar concentrations in the hydrolysates from the two-step pretreatment at four temperatures in the second pretreatment with hot water. There was no significant difference in sugar yield when the temperature in the second pretreatment was increased from 120 to $165^{\circ} \mathrm{C}$. The highest glucan conversion obtained in this experiment was $83 \%$ at $135^{\circ} \mathrm{C}$. Compared to the one-step pretreatment reported in Figure 1, the glucose concentrations in the hydrolysats were much higher, and the glucan conversion yields in the two-step pretreatment were all as high as 

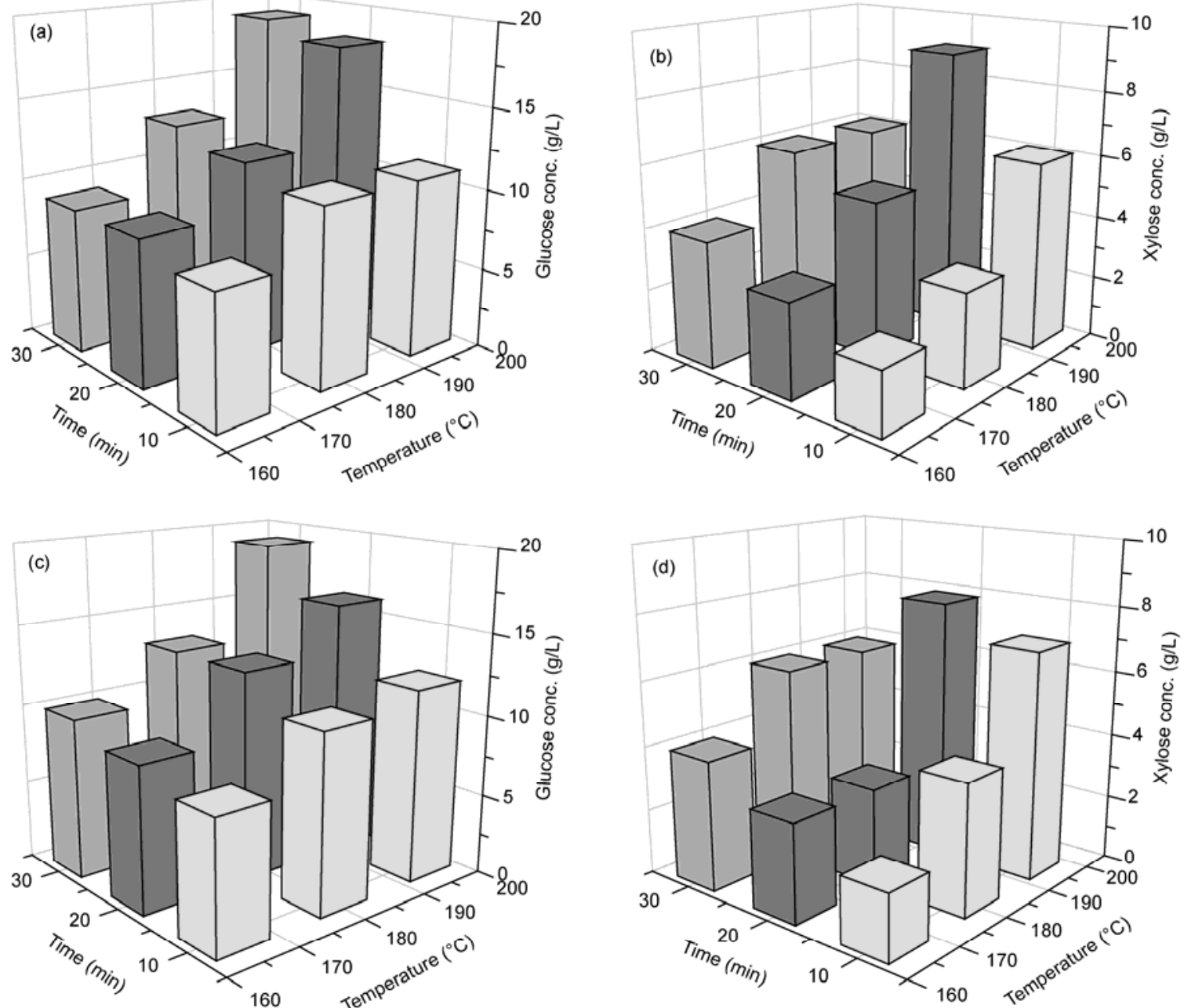

Figure 1 Sugars concentrations of corn stover pretreated by electrolyzed water pretreatment. (a) and (b): glucose and xylose in the AEW pretreatment process; (c) and (d): glucose and xylose in the ALEW pretreatment process.

that of the highest yield in one-step pretreatment at lower temperatures. This may indicate that the samples with lignin partially removed in the first step pretreatment had a desirable surface structure, providing good contact of the enzymes with the cellulose, resulting in a high glucose yield. More importantly, it reduced the requirement for the second pretreatment and, as a result, the treatment temperature in the second pretreatment did not have a significant effect on the final sugar yield, as shown in Figure 2.

Table 1 summarizes the cellulose conversion yields of corn stover pretreated by selected pretreatment methods, which have been under investigation for over 20 years $[7,9,25,26]$. It can be seen that the cellulose conversion yields of corn stover pretreated by electrolyzed water and the two-step method are higher than that obtained from the diluted sulfuric acid pretreatment, but lower than those of other methods (ARP, AFEX and lime). The differences may be caused by the composition of the corn stover used. It is known that the composition of biomass is affected by many environmental factors, such as weather conditions and soil

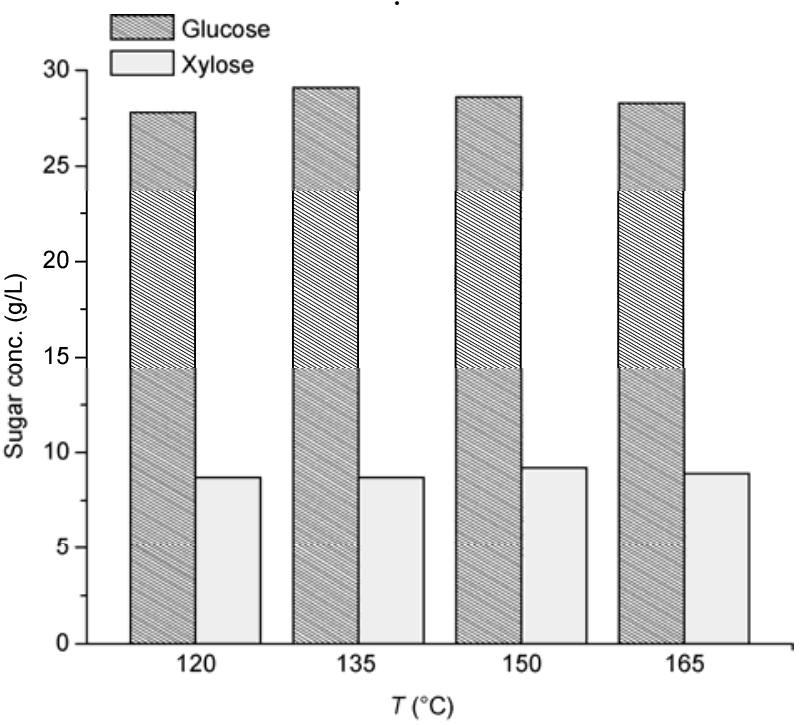

Figure 2 Sugar concentrations of corn stover pretreated by the two-step pretreatment method. 
Table 1 Cellulose conversion yields of corn stover pretreated by different methods (15FPU cellulase $\mathrm{g}^{-1}$ cellulose)

\begin{tabular}{|c|c|c|c|}
\hline Pretreatment & Conditions & Conversion yield $(\%)$ & Reference \\
\hline Diluted sulfuric acid & $5 \mathrm{wt} \%$ solid loading; $4.9 \%$ sulfuric acid; $160^{\circ} \mathrm{C} ; 20 \mathrm{~min}$ & 57.1 & [7] \\
\hline $\begin{array}{l}\text { Ammonia recycle percolation } \\
\text { (ARP) }\end{array}$ & $15 \mathrm{wt} \%$ ammonia liquid; $2.5 \mathrm{MPa} ; 5.0 \mathrm{~mL} / \mathrm{min} ; 60 \mathrm{~min}$ & $\sim 87.1$ & [25] \\
\hline Lime & $0.5 \mathrm{~g} \mathrm{Ca}(\mathrm{OH})_{2} / \mathrm{g}$ biomass; $55^{\circ} \mathrm{C} ; 4$ weeks & 91.3 & [26] \\
\hline Electrolyzed water & $12.5 \mathrm{wt} \%$ solid loading; AEW; $195^{\circ} \mathrm{C} ; 30 \mathrm{~min}$ & 83 & - \\
\hline
\end{tabular}

conditions, amongst others. The corn stover used by different groups thus may have different lignin content, with high lignin corresponding to high resistance to decomposition. On the other hand, the physical properties of the corn stover, such as particle size, surface and internal porosity, and surface area, among others, vary from batch to batch, and can also cause a difference in sugar yield. In addition, as recently developed pretreatments, both the electrolyzed water and the two-stage methods have potential for further development and optimization.

\subsection{Fermentation}

Table 2 summarizes the information on the fermentation broth, as well as the fermentation data of the glucose solution and the corn stover hydrolysates from the one-step electrolyzed water pretreatment and the two-step pretreatment. The hydrolysate from the one-step electrolyzed water pretreatment was obtained from samples pretreated with $\mathrm{AEW}$ at $195^{\circ} \mathrm{C}$ and $30 \mathrm{~min}$, while the hydrolysate from the two-step pretreatment had a reaction temperature of $135^{\circ} \mathrm{C}$ in the second step pretreatment. In HPLC analysis, there was no furfural or HMF detected in either hydrolysate, while the acetic acid concentration was 0.38 and $0.23 \mathrm{~g} / \mathrm{L}$ in the hydrolysates from the AEW one-step pretreatment and the two-step pretreatment, respectively. The fermentations of hydrolysates were conducted without detoxification, concentration or nutrient addition. The final ethanol concentration was $6.1 \mathrm{~g} / \mathrm{L}$ in the hydrolysate from the AEW one-step pretreatment, while the final ethanol concentration in the hydrolysate from the two-step pretreatment was $12 \mathrm{~g} / \mathrm{L}$.
The $78 \%$ of the theoretical productive yield was reached in the fermentation of the hydrolysate from the two-step pretreatment, while that for the one-step pretreatment samples was $63 \%$. Because the xylose in the hydrolysates $(5.7 \mathrm{~g} / \mathrm{L}$ in the one-step samples and $8.7 \mathrm{~g} / \mathrm{L}$ in the two-step pretreated samples) was not used during the Baker's yeast fermentation, the ethanol production could be increased if a glucose-xylose co-fermenting yeast was used.

The detailed information for the fermentation of the glucose solution and the hydrolysates is shown in Figure 3. During the glucose solution fermentation, the ethanol production started early and about $2.0 \mathrm{~g} / \mathrm{L}$ ethanol was detected at $5 \mathrm{~h}$. The glucose was completely consumed at $48 \mathrm{~h}$ when the ethanol concentration reached its maximum (Figure 3(a)). The fermentation of the hydrolysate from the two-step pretreatment is shown in Figure 3(b). No significant delay in ethanol production and cell growth can be observed and about $1.0 \mathrm{~g} / \mathrm{L}$ ethanol was obtained at $5 \mathrm{~h}$. The glucose was used up at $96 \mathrm{~h}$, when the highest ethanol concentration was obtained. The ethanol yield, sugar consumption, and cell growth for the fermentation of the hydrolysate from the one-step pretreatment are shown in Figure 3(c). It can be seen that the fermentation was significantly delayed and the ethanol production was not observed until at $24 \mathrm{~h}$, when an ethanol concentration of $0.2 \mathrm{~g} / \mathrm{L}$ was detected. The glucose consumption was slow but at $96 \mathrm{~h}$ most of the glucose had been consumed and, as a result, the highest ethanol concentration was detected.

Furfural and HMF are formed during pretreatment when small amounts of monosaccharides (pentoses and hexoses) released from biomass are degraded under acidic conditions.

Table 2 Information on fermentation broths and fermentation results

\begin{tabular}{lccc}
\hline \multicolumn{1}{c}{ Concentration $(\mathrm{g} / \mathrm{L})$} & Glucose solution & Hydrolysate from 2-step pretreatment & Hydrolysate from one-step pretreatment \\
\hline Glucose & 27 & 30.2 & 8.7 \\
Xylose & 0 & 0.23 & 5.7 \\
Acetic acid & 0 & - & 0.38 \\
HMF & 0 & - & - \\
Furfural & 0 & 12 & - \\
Ethanol & 12.3 & 0.78 & 0.1 \\
Productive yield & 0.89 & 0.63
\end{tabular}



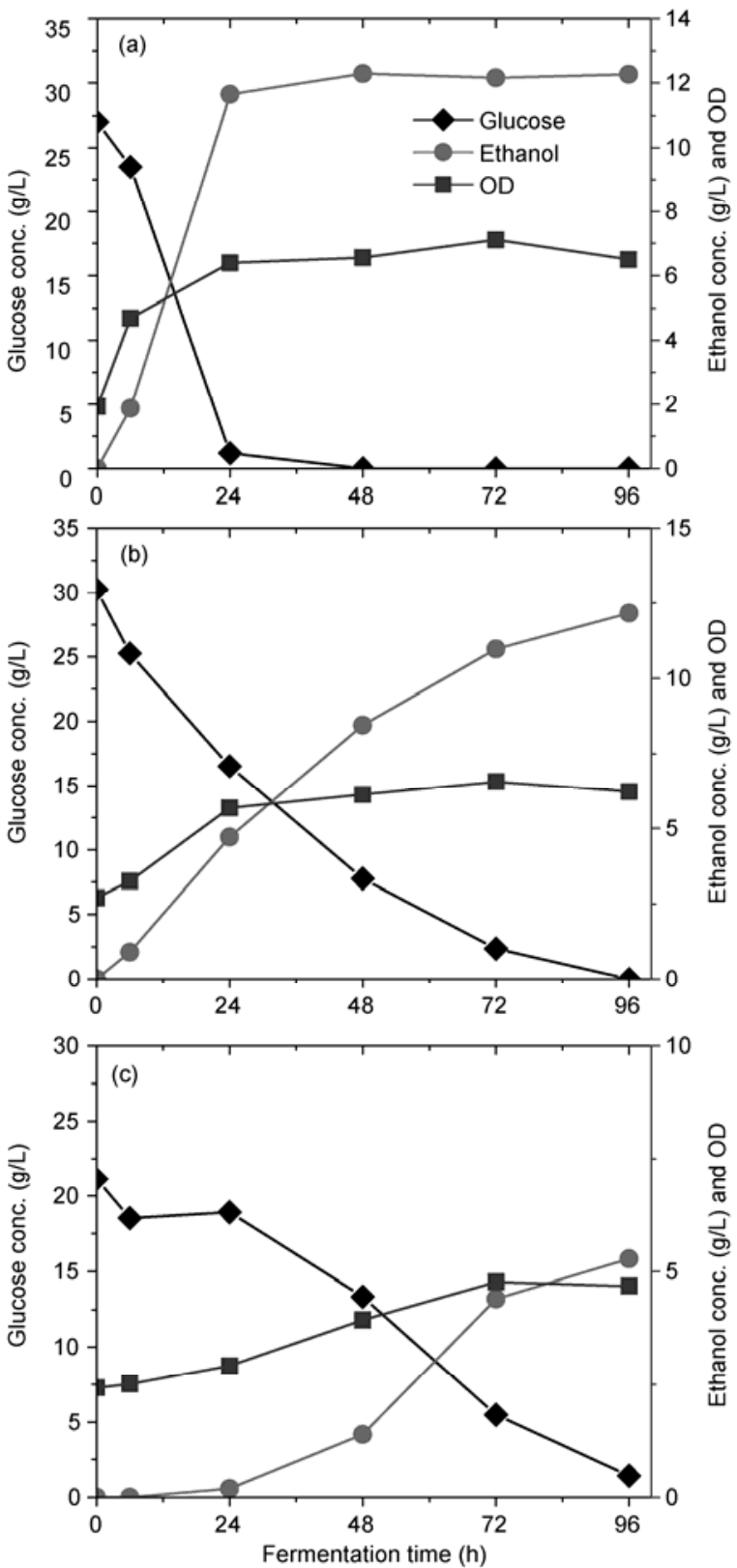

Figure 3 Fermentation results of glucose solution and hydrolysates from AEW pretreatment and 2-step pretreatments. (a) glucose solution; (b) hydrolysate from 2-step pretreatment; (c) hydrolysate from AEW pretreatment.

These are considered as inhibitors for ethanol fermentation [27]. They could be further broken down to formic acid and levulinic acid. HMF and furfural could be consumed during yeast fermentation, while the rate of furfural consumption was a little faster. Furfural could be reduced by yeast cells to furfuryl alcohol during fermentation and cause a lag-phase in the ethanol formation but it does not affect the final ethanol yield [28].

The minimum concentration of furfural and HMF that could be tested was $0.2 \mathrm{~g} / \mathrm{L}$ in the HPLC system used in this study. Therefore, if present at all in the hydrolysate, the furfural and HMF concentration should be $<0.2 \mathrm{~g} / \mathrm{L}$. Small amounts of acetic acid, $(0.23 \mathrm{~g} / \mathrm{L}$ for the two-step and 0.38 $\mathrm{g} / \mathrm{L}$ for the one-step pretreatment) detected in the hydrolysates was liberated from xylan degradation and its effect on fermentation is $\mathrm{pH}$-dependant. It has been reported that 50\% inhibition of cell growth or fermentation would occur in the yeast when the acetic acid concentration reaches $4.3 \mathrm{~g} / \mathrm{L}$ [29]. Therefore, the observed fermentation delay in Figure 3 (b) and (c) might have been caused by a compounded action of small amounts of furfural and HMF, as well as low concentrations of phenolic compounds that could be present in the hydrolysates after pretreatment. A detailed inhibitor analysis, including commonly observed phenolic compounds in biomass hydrolysates, should be conducted in future studies to elucidate the role played by those lowconcentration inhibitors during the fermentation.

\section{Conclusions}

An electrolyzed water one-step pretreatment and a two-step pretreatment using alkaline-organic solution both successfully deconstructed corn stover for ethanol production. The hydrolysates from the AEW one-step pretreatment and the alkaline-organic solution plus hot water two-step pretreatment can be used for fermentation without concentration, detoxification or nutrient addition. The highest glucan conversion $(83 \%)$ was achieved with the hydrolysate obtained from the two-step pretreatment, when the temperature in the second step was $135^{\circ} \mathrm{C}$. The highest productive yield was 0.78 , from fermentation of hydrolysate with the highest glucan conversion yield from the two-step pretreatment.

Xiaojuan Wang was supported by China Scholarship Council with a twoyear fellowship to study in University of Illinois at Urbana \& Champaign.

1 Wyman C E. What is (and is not) vital to advancing cellulosic ethanol. Trend Biotechnol, 2007, 25: 153-157

2 Yang B, Wyman C E. Pretreatment: The key to unlocking low-cost cellulosic ethanol. Biofuel Bioprod Bioref, 2008, 2: 26-40

3 Pampulha M E, Loureiro V. Interaction of the effects of acetic acid and ethanol on inhibition of fermentation in Saccharomyces cerevisiae. Biotechnol Lett, 1989, 11: 269-274

4 Varga E, Reczey K, Zacchi G. Optimization of steam pretreatment of corn stover to enhance enzymatic digestibility. Appl Biochem Biotechnol, 2004, 113-116: 509-523

5 Sassner P, Galbe M, Zacchi G. Steam pretreatment of salix with and without $\mathrm{SO}_{2}$ impregnation for production of bioethanol. Appl Biochem Biotechnol Prog, 2005, 121-124: 1101-1117

6 Liu C, Wyman C E. Partial flow of compressed-hot water through corn stover to enhance hemicellulose sugar recovery and enzymatic digestibility of cellulose. Bioresour Technol, 2005, 96: 1978-1985

7 Lloyd T A, Wyman C E. Combined sugar yields for dilute sulfuric acid pretreatment of corn stover followed by enzymatic hydrolysis of the remaining solids. Bioresour Technol, 2005, 96: 1967-1977

8 Moiser N, Hendrickson R, Ho N, et al. Optimization of $\mathrm{pH}$ controlled liquid hot water pretreatment of corn stover. Bioresour Technol, 2005, 96: 1986-1993

9 Teymouri F, Laureano-Perez L, Alizadeh H, et al. Optimization of the ammonia fiber explosion (AFEX) treatment parameters for enzymatic hydrolysis of corn stover. Bioresour Technol, 2005, 96: 
2014-2018

10 Wang B, Ezeji T, Shi Z, et al. Pretreatment and conversion of Distiller's dried grains with solubles for Acetone-Butanol-Ethanol (ABE) production. Transact ASABE, 2009, 52: 885-892

11 Wang B, Wang X J, Feng H. Deconstructing recalcitrant Miscanthus with alkaline peroxide and electrolyzed water. Bioresour Technol, 2010, 101: 752-760

$12 \mathrm{Lu} \mathrm{Y}$, Yang B, Gregg D, et al. Cellulase adsorption and an evaluation of enzyme recycle during hydrolysis of steam-exploded softwood residues. Appl Biochem Biotechnol, 2002, 98-100: 641-654

13 Yang B, Wyman C E. BSA treatment to enhance enzymatic hydrolysis of cellulose in lignin containing substrates. Biotechnol Bioeng 2006, 94: 611-617

14 Hames B, Ruiz R, Scarlata C, et al. Preparation of samples for compositional analysis laboratory analytical procedure (LAP). Colorado: National Renewable Energy Lab, 2008. http://www.nrel.gov/biomass/ pdfs/42620.pdf

15 Sluiter A, Ruiz R, Scarlata C, et al. Determination of extractives in biomass laboratory analytical procedure (LAP). Colorado: National Renewable Energy Lab, 2005. http: //app.moogo.com/files/biomass.moogo. com/files/biomass_analysis_precedure/determination_of_extractives_ in_biomass.pdf

16 Sluiter A, Hames B, Ruiz R, et al. Determination of structural carbohydrates and lignin in biomass laboratory analytical procedure (LAP). Colorado: National Renewable Energy Lab, 2008. http://www.nrel. gov/biomass/pdfs/42618.pdf

17 Adney B, Baker J. Measurement of cellulase activities (LAP). Colorado. National Renewable Energy Lab, Colorado, 1996. http://www. nrel.gov/biomass/pdfs/42628.pdf

18 Ghose T. Measurement of cellulase activities. Pure Appl Chem, 1987, 59: $257-268$
19 Miller G. Use of dinitrosalicylic acid reagent for determination of reducing sugar. Anal Chem, 1959, 31: 426-428

20 Horvath I S, Sjode A, Alriksson B, et al. Critical conditions for improved fermentability during overliming of acid hydrolysates from spruce. Appl Biochem Biotechnol, 2005, 121-124: 1031-1044

21 Xiang Q, Lee Y, Torget R. Kinetics of glucose decomposition during dilute-acid hydrolysis of lignocellulosic biomass. Appl Biochem Biotechnol, 2004, 113-116: 1127-1139

22 Ohgren K, Galbe M, Zacchi G. Optimization of steam pretreatment of $\mathrm{SO}_{2}$-impregenated corn stover for fuel ethanol production. Appl Biochem Biotechnol, 2005, 121-124: 1055-1067

23 Qian X, Nimlos M, Johnoson D, et al. Acidic sugar degradation pathways. Appl Biochem Biotechnol, 2005, 121-124: 989-997

24 Usuki C, Kimura Y, Adachi S. Degradation of pentoses and hexouronic acids in subcritical water. Chem Eng Technol, 2008, 31: 133-137

25 Kim T H, Lee Y Y. Pretreatment and fractionation of corn stover by ammonia recycle percolation process. Bioresour Technol, 2005, 96: 2007-2013

26 Kim S, Holtzapple M T. Lime pretreatment and enzymatic hydrolysis of corn stover. Bioresour Technol, 2005, 96: 1994-2006

27 Endo A, Nakamura T, Ando A, et al. Genome-wide screening of the genes required for tolerance to vanillin, which is a potential inhibitor of bioethanol fermentation, in Saccharomyces cerevisiae. Biotechnol Biofuels, 2008, 1: 3-10

28 Villa G P, Bartroli R, Lopez R, et al. Microbial transfonnation of furfural to furfuryl alcohol by Saccharomyces cerevisiae. Acta Biotechnol, 1992, 12: 509-512

29 Pampulha M E, Loureiro V. Interaction of the effects of acetic acid and ethanol on inhibition of fermentation in Saccharomyces cerevisiae. Biotechnol Lett, 1989, 11: 269-274

Open Access This article is distributed under the terms of the Creative Commons Attribution License which permits any use, distribution, and reproduction in any medium, provided the original author(s) and source are credited. 